\title{
Guidance on contraception for women aged over 40 years
}

I read the guidance on contraception for women aged over 40 years with interest. ${ }^{1}$ Table 4 on page 9 states that the use of progestogen-only methods in women with current venous thromboembolism (VTE) (on anticoagulants) is considered UKMEC 2. It conflicts with previous publications of the Clinical Effectiveness Unit on progestogen-only injectables ${ }^{2}$ and implants. ${ }^{3}$ The use of a progestogen-only injectable or implant in women with a current VTE (on anticoagulants) was classified as UKMEC 3. I would be grateful for an explanation of this discrepancy.

Page 10 of the guidance on contraception for women aged over 40 years reports the following: "Caution is required when prescribing DMPA [depot medroxyprogesterone acetate] to women with cardiovascular risk factors due to the effects of progestogens on lipids". Table 4 on page 9 considers hypertension that is adequately controlled as UKMEC 2 , consistently elevated blood pressure over 140 systolic/over 90 diastolic as UKMEC 1 and blood pressure of 160 or over/95 $\mathrm{mm} \mathrm{Hg}$ or over as UKMEC 2 for the use of the progestogen-only injectable (DMPA). ${ }^{1}$ This current advice 
is illogical as uncontrolled hypertension is considered UKMEC 1 or 2 while controlled blood pressure is UKMEC 2 . Taking into account that hypertension is one of the risk factors for cardiovascular disease and the adverse effects of DMPA on lipids, its use in uncontrolled hypertension should be classified as UKMEC 3 or 4 depending on the measured values of blood pressure.

Nader Al-Hassan, MRCGP, DFSRH

Richard-Wagner-Strasse 10, 68649 Gross-Rohrheim, Germany; naderalhassan@hotmail.com

\section{Competing interests None.}

J Fam Plann Reprod Health Care 2011;37:124-125. doi:10.1136/fprhc.2011.0065

\section{REFERENCES}

1 Faculty of Sexual and Reproductive Healthcare Clinical Effectiveness Unit. Contraception for Women Aged Over 40 Years. 2010. http://www.fsrh.org/admin/uploads/ Contraception0ver40July10.pdf [accessed 15 January 2011].

2 Faculty of Sexual and Reproductive Healthcare Clinical Effectiveness Unit.

Progestogen-only Injectable Contraception. 2009. http://www.fsrh.org/admin/uploads/ CEUGuidanceProgestogenOnlylnjectables09.pdf [accessed 15 January 2011].

3 Faculty of Sexual and Reproductive Healthcare Clinical Effectiveness Unit. Progestogen-only Implants. 2008. http://www.fsrh.org/admin/uploads/

CEUGuidanceProgestogenOnlylmplantsApril08. pdf [accessed 15 January 2011]. 